\title{
PROPOSTA PEDAGÓGICA DE ENSINO DE FUNÇÃO AFIM ATRAVÉS DA MODELAGEM MATEMÁTICA
}

\author{
$\underline{\text { Dayani Quero da Silva }}{ }^{1}$ \\ Universidade Tecnológica Federal do Paraná - Licenciatura em Matemática \\ Campus Cornélio Procópio, PR \\ E-mail: day_dayani@ @otmail.com \\ Milton Kist \\ Universidade Tecnológica Federal do Paraná - Coordenação de Matemática \\ Campus Cornélio Procópio, PR \\ E-mail: miltonkist@utfpr.edu.br
}

\begin{abstract}
RESUMO
Este trabalho tem por objetivo descrever uma proposta pedagógica da Universidade Tecnológica Federal do Paraná - Câmpus Cornélio Procópio (UTFPR - CP) através da atuação de alunos do curso de Licenciatura em Matemática no Programa Institucional de Bolsa de Iniciação à Docência (PIBID). A experiência será realizada em um colégio privado na área central de Cornélio Procópio - Paraná, em uma turma de primeiro ano de Ensino Médio com quarenta alunos. Esta experiência terá abordagem no conteúdo disciplinar de Função Afim. Foram feitas várias observações e participações na turma e percebeu - se uma grande defasagem e dificuldades de entendimento através do método tradicional de ensino e isso fez com que se repensasse na prática docente adotada objetivando a aplicação de uma nova perspectiva metodológica.
\end{abstract}

Neste contexto, a Modelagem Matemática foi selecionada para aplicação em quatro aulas da disciplina de matemática, totalizando 200 minutos. A utilização dessa metodologia contribui para uma aprendizagem mais significativa, motivando a participação dos alunos.

A modelagem matemática, segundo Bassanezi (2002) "é a arte de transformar problemas da realidade em problemas matemáticos e resolvê-los interpretando suas soluções na linguagem do mundo real".

E, segundo Souza (1998): "desenvolver a capacidade de pensar permite que o ser humano deixe de lado sua condição de ser objeto, alienado, passivo e passe a fazer parte da sociedade como ser atuante, ativo, inteligente, sujeito de suas histórias", ou seja, é importante que o professor desenvolva atividades que promovam a curiosidade e a reflexão de cada aluno.

A atividade terá o objetivo de explorar o conteúdo de Função Afim através dos planos de telefonia celular oferecidos pelas operadoras, analisando determinados planos.

\footnotetext{
${ }^{1}$ Bolsista PIBID e aluna do Curso de Licenciatura em Matemática da UTFPR-CP.
} 
Foi escolhido esse tema relacionado à telefonia para abordagem do conteúdo disciplinar Função Afim, visto que, os alunos estão constantemente antenados ao uso de tecnologia, principalmente às celulares, no ambiente escolar.

Acredita - se que o trabalho privilegiará a colaboração e a cooperação entre os alunos na realização da atividade.

A princípio deve - se realizar uma pesquisa com os alunos da turma questionando - os sobre o uso do celular e encaminhar textos para que façam a leitura para realizar um debate em um segundo momento.

Após o debate, é interessante que os alunos passem a desenvolver a seguinte atividade:

\section{Idec diz que telefonia celular ainda é cara no Brasil}

O Instituto Brasileiro de Defesa do Consumidor (Idec) enviou para a Comissão de Defesa do Consumidor da Câmara um estudo que mostra que o brasileiro ainda paga muito pela linha de telefone celular e faz pouco uso desse serviço, em razão das altas tarifas. O Idec também apontou que o serviço figura ainda, junto com outros serviços de telecomunicações, dentre os com maior incidência de reclamação nos órgãos de defesa do consumidor.

"Na avaliação do Idec, os altos custos são resultado da falta de uma regulação mais forte para o setor. Por se tratar de um serviço prestado em regime privado, as tarifas praticadas na telefonia móvel são definidas pelas próprias operadoras, que devem somente comunicá-las ao órgão regulador", destaca o documento do órgão.

Outra reclamação do Idec diz respeito à diferença de preço entre os planos pós-pago e pré-pago. O custo do último, usado por $80 \%$ da população, chega a ser duas vezes maior do que o do pré-pago. A expectativa do Idec é que a contribuição à comissão possa levar a um maior respeito por parte das empresas às normas mais básicas de proteção ao consumidor (como o Código de Defesa do Consumidor).

Medidas preventivas e repressivas por parte da Anatel são essenciais a fim de tornar o custo do serviço menor, além da necessidade de haver mais fiscalização sobre oferta, publicidade, contratos e relações póscontratuais, com punições mais efetivas - afirma a advogada do Idec Estela Guerrini.

O valor a ser pago, em uma determinada conta telefônica, é dado em função dos minutos (tempo) utilizados mais um valor fixo pelo cliente. No quadro abaixo, são apresentados três planos de telefonia celular. 
Tabela 1: Planos de telefonia celular pós pago.

\begin{tabular}{ccc}
\hline PLANO & CUSTO FIXO & CUSTO ADICIONAL POR MINUTOS \\
\hline $\mathbf{1}$ & $\mathrm{R} \$ 35,00$ & $\mathrm{R} \$ 0,50$ \\
$\mathbf{2}$ & $\mathrm{R} \$ 20,00$ & $\mathrm{R} \$ 0,80$ \\
$\mathbf{3}$ & $\mathrm{R} \$ 0,00$ & $\mathrm{R} \$ 1,20$ \\
\hline
\end{tabular}

Hipótese: o custo da conta telefônica depende dos minutos utilizados mais um valor fixo.

a) Qual é o plano mais vantajoso para alguém que utilize no máximo 25 min por mês?

b) A partir de quantos minutos de uso mensal o plano A é mais vantajoso do que os outros dois?

c) Escreva a expressão matemática de formação dos três planos.

d) Qual o valor gasto no plano mais vantajoso usando 45 min $25 \mathrm{seg}$. 32"'?

e) Construa os gráficos das funções cujo domínio IR.

f) Em sua opinião, o plano pós pago é mais vantajoso do que o pré pago? Justifique sua resposta.

Análise: Se você gerenciasse uma empresa e tivesse que convencer os seus diretores a optar por um dos planos acima qual argumento utilizaria? Comprove para os mesmo as vantagens do plano escolhido.

Palavras-chave: Metodologia de Ensino da Matemática, Modelagem Matemática, Ensino de Função Afim.

\section{Referências}

[1] BASSANEZI, R. C. Ensino-aprendizagem com modelagem matemática: uma nova estratégia. São Paulo: Contexto, 2002.

[2] CAMELO, S.M. Estudo de Função Afim Através da Modelagem Matemática. Campina Grande: 2013. Disponível em: < http://www.dme.ufcg.edu.br/PROFmat/TCC/soraya.pdf>. Acesso em: 20 set. 2013.

[3] GLOBO. Idec diz que telefonia celular ainda é cara no Brasil. Disponível em: $<$ http://oglobo.globo.com/economia/idec-diz-que-telefonia-celular-ainda-cara-no-brasil3006744> Acesso em: 08 set. 2013.

[4] SOUZA, N. A. in Conferência da Seletiva de Mestrado. Educar é Desenvolver a Capacidade de Pensar. FURB -14/11/1998. Disponível em: <http://www.unescnet.br/revistaeletronica/Pedagogia/direito11.htm>. Acesso em: 08 set. 2013. 